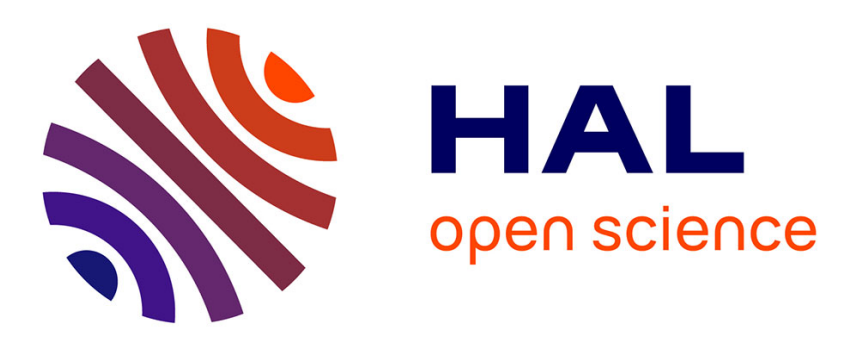

\title{
Rupture Process of the Mw 3.3 Earthquake in the St. Gallen 2013 Geothermal Reservoir, Switzerland
} Eszter Király-Proag, Claudio Satriano, Pascal Bernard, Stefan Wiemer

\section{To cite this version:}

Eszter Király-Proag, Claudio Satriano, Pascal Bernard, Stefan Wiemer. Rupture Process of the Mw 3.3 Earthquake in the St. Gallen 2013 Geothermal Reservoir, Switzerland. Geophysical Research Letters, 2019, 46, pp.7990-7999. 10.1029/2019GL082911 . insu-03586637

\section{HAL Id: insu-03586637 https://hal-insu.archives-ouvertes.fr/insu-03586637}

Submitted on 24 Feb 2022

HAL is a multi-disciplinary open access archive for the deposit and dissemination of scientific research documents, whether they are published or not. The documents may come from teaching and research institutions in France or abroad, or from public or private research centers.
L'archive ouverte pluridisciplinaire HAL, est destinée au dépôt et à la diffusion de documents scientifiques de niveau recherche, publiés ou non, émanant des établissements d'enseignement et de recherche français ou étrangers, des laboratoires publics ou privés.

$$
\text { Copyright }
$$




\section{Geophysical Research Letters}

\author{
RESEARCH LETTER \\ 10.1029/2019GL082911 \\ Key Points: \\ - Our approach reveals rupture \\ complexity for a magnitude 3.3 \\ fluid-induced earthquake at $100-\mathrm{m}$ \\ scale \\ - The rupture propagated toward NNE \\ breaking into a previously less active \\ portion of the fault \\ - Early aftershocks distribute around \\ the main slip area, suggesting a stress \\ transfer mechanism
}

Supporting Information:

- Supporting Information S1

Correspondence to:

C. Satriano,

satriano@ipgp.fr

Citation:

Király-Proag, E., Satriano, C., Bernard, P., \& Wiemer, S. (2019). Rupture process of the $M_{w} 3.3$ earthquake in the St. Gallen 2013 geothermal reservoir, Switzerland. Geophysical Research Letters, 46, 7990-7999. https://doi.org/10.1029/ 2019GL082911

Received 19 MAR 2019

Accepted 5 JUL 2019

Accepted article online 9 JUL 2019

Published online 22 JUL 2019

(C)2019. American Geophysical Union. All Rights Reserved.

\section{Rupture Process of the $M_{w} 3.3$ Earthquake in the St. Gallen 2013 Geothermal Reservoir, Switzerland}

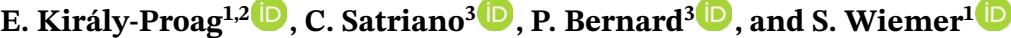 \\ ${ }^{1}$ Swiss Seismological Service, ETH Zurich, Zurich, Switzerland, ${ }^{2}$ Now at Swiss Re Management Ltd., Zurich, \\ Switzerland, ${ }^{3}$ Institut de physique du globe de Paris, CNRS, Université de Paris, Paris, France
}

Abstract We analyze slip distribution and rupture kinematics of a $M_{w} 3.3$ induced event that occurred in the St. Gallen geothermal reservoir (NE Switzerland) in 2013. We carry out a two-step procedure: (1) path effects are deconvolved from the seismograms using an empirical Green's function, resulting in relative source time functions at all seismic stations; (2) the relative source time functions are back-projected to the corresponding isochrones on the fault plane. Results reveal that the mainshock rupture propagates toward NNE from the hypocenter with an average velocity of $2,000 \mathrm{~m} / \mathrm{s}$. Spatiotemporal organization of foreshocks and aftershocks shows that the mainshock broke a previously less active portion of the fault and suggests that the aftershock sequence could be mainly driven by stress transfer. Applying this method in an operational environment could enable fast retrieval of seismic slip, allowing assessment of fault asperities and structures involved in the reservoir creation process.

Plain Language Summary In most models and analyses, small earthquakes (i.e., magnitude less than 4) are considered either point sources or homogeneous "penny-shaped" surfaces. While these assumptions may be valid, details of earthquake ruptures are more complex. Here we study a magnitude 3 induced earthquake that occurred in the St. Gallen geothermal reservoir (NE Switzerland) in 2013. We image the earthquake rupture by refocusing on the fault the seismic energy recorded at six sensors located within $15 \mathrm{~km}$ from the source. Our results show that a detailed description of the rupture process of such a small earthquake can indeed be obtained: The rupture propagates from the hypocenter in NNE direction for $150 \mathrm{~m}$, with an average velocity of $2 \mathrm{~km} / \mathrm{s}$, breaking into a less active portion of the fault, where no earthquake was previously recorded. The proposed method could be routinely applied during geothermal reservoir operations to allow rapid assessment of fault structures involved in the reservoir creation process.

\section{Introduction}

Induced seismicity (i.e., earthquakes caused by human activity) is an increasingly debated topic in scientific literature and in public media (Ellsworth, 2013; Grigoli et al., 2017). Among the industrial activities that can produce earthquakes, geothermal projects receive particular attention due to the rising importance of alternative energy. Economical exploitation of geothermal energy requires sufficient fluid that circulates through connected channels in a hot medium (Hirschberg et al., 2015). In certain cases, it becomes necessary to enhance the permeability of the target rock formation, which is one of the main challenges. As induced earthquakes are the best indicators of permeability creation to date, geothermal projects are generally monitored by close dedicated seismic networks. Microseismicity is routinely detected and located (e.g., Albaric et al., 2014; Atkinson et al., 2016; Baisch et al., 2009; Deichmann et al., 2014; Diehl et al., 2017; Schoenball et al., 2018), characterized (i.e., magnitudes, focal mechanisms, moment tensors, stress drops, and source areas; e.g., Deichmann \& Giardini, 2009; Edwards \& Douglas, 2014; Edwards et al., 2015; Goertz-Allmann et al., 2011; Guilhem \& Walter, 2015; Huang et al., 2017; Kraft \& Deichmann, 2014), and modeled (e.g., Bachmann et al., 2011; Catalli et al., 2016; Gischig \& Wiemer, 2013; Karvounis \& Wiemer, 2015; Langenbruch \& Shapiro, 2010; Langenbruch \& Zoback, 2016; Mena et al., 2013; Rutqvist, 2011; Segall \& Lu, 2015).

In most models and analyses, earthquakes are considered either point sources or "penny-shaped" surfaces with homogeneous source properties. While these assumptions may be valid, details of individual 


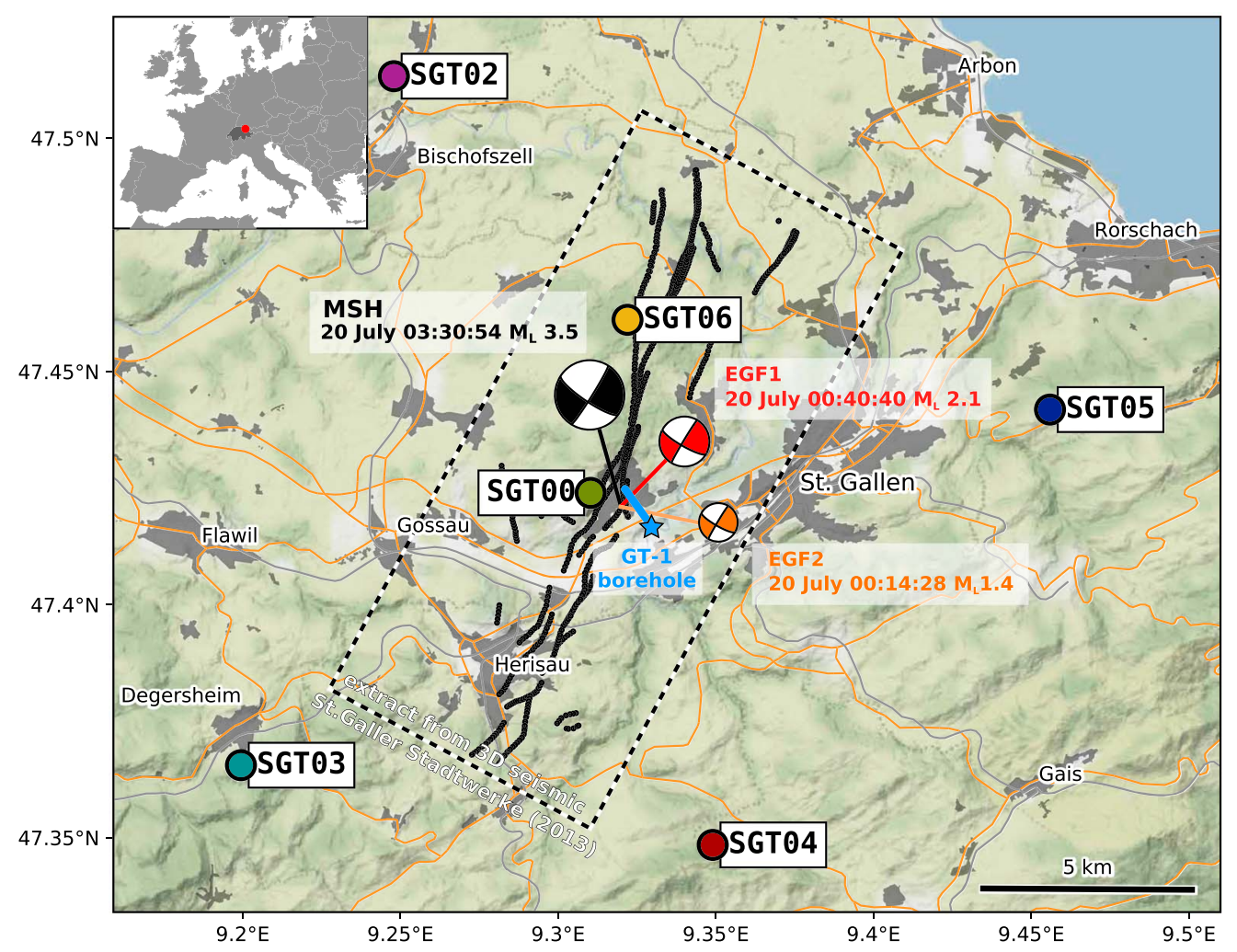

Figure 1. Study area in NE Switzerland. Colored circles denote stations used in this study. SGT00 is a borehole station; others are surface installations. The head of the GT-1 drilling borehole is shown by a blue star, while the blue line indicates the borehole surface projection. Solid black lines show the St. Gallen Fault Zone (an extract from 3-D seismic exploration by the operator St. Galler Stadtwerke; Heuberger et al., 2016). Focal mechanisms (Diehl et al., 2017) of the mainshock (black), and the $M_{L} 2.1$ event (EGF1 in red) are represented. A smaller $M_{L} 1.4$ event (EGF2 in orange) is also shown; its focal mechanism is not available: here we attribute the same mechanism as the EGF1 based on waveform similarity. Inset shows the location of the region.

earthquakes are more complex. Due to the insufficient resolution of most monitoring networks, micro-earthquakes $(M<2)$ must be still approximated as dislocation on penny-shaped surfaces. But in case of larger events $(M>3)$ recorded on well-distributed local seismic stations, detailed slip patterns within the rupture area can be imaged. Previous studies of small to moderate earthquakes of natural origin showed that, similarly to large earthquakes, they exhibit rupture directivity (e.g., Abercrombie et al., 2017; Boatwright, 2007; McGuire, 2002) and spatial variability in slip distribution (e.g., Dreger et al., 2007; Ide, 2001; Kim et al., 2016; McGuire, 2004). Imaging and modeling the rupture kinematics of earthquakes can contribute to the understanding of the structures associated with rupture nucleation, propagation, slipped asperities, and seismic radiation (e.g., Mai, 2005). Moreover, the comparison of the kinematic slip image with the space-time distribution of earthquakes that occurred before and after can provide insights into the load processes leading to seismic failure on those structures (e.g., Stein, 2003). Slip distributions can also serve as an input or independent information for modeling. For instance, the slip distribution of larger events is required for models incorporating static stress change triggered by earthquakes, or hydromechanical models that require a relationship between slip and hydraulic aperture (e.g., Rutqvist, 2011).

In this study, we examine the slip distribution and the rupture kinematics of a $M_{w} 3.3\left(M_{L} 3.5\right)$ induced event that occurred in the St. Gallen geothermal reservoir (NE Switzerland, Figure 1) on 20 July 2013, which was widely felt in the region (Edwards et al., 2015). The industrial project was inspired by hydrothermal systems where hot water is extracted from a deep natural reservoir (e.g., Evans et al., 2012). To test and improve the connectivity between the well and the naturally fractured aquifers, for example, fault zones, a hydraulic test and two acid stimulations were carried out in July 2013, immediately followed by seismic events (Diehl et al., 2017; Wolfgramm et al., 2015). On 19 July, methane gas was detected in the borehole. To reduce the pressure buildup, drilling mud was pumped into the well, increasing significantly the micro-earthquake 

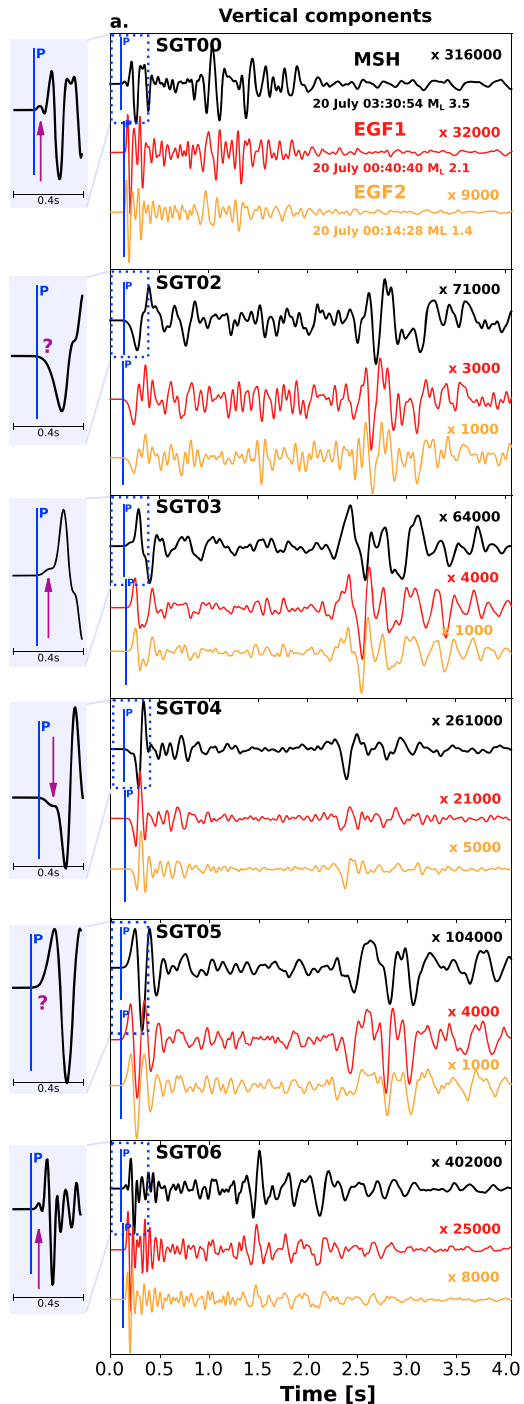

Time [s]
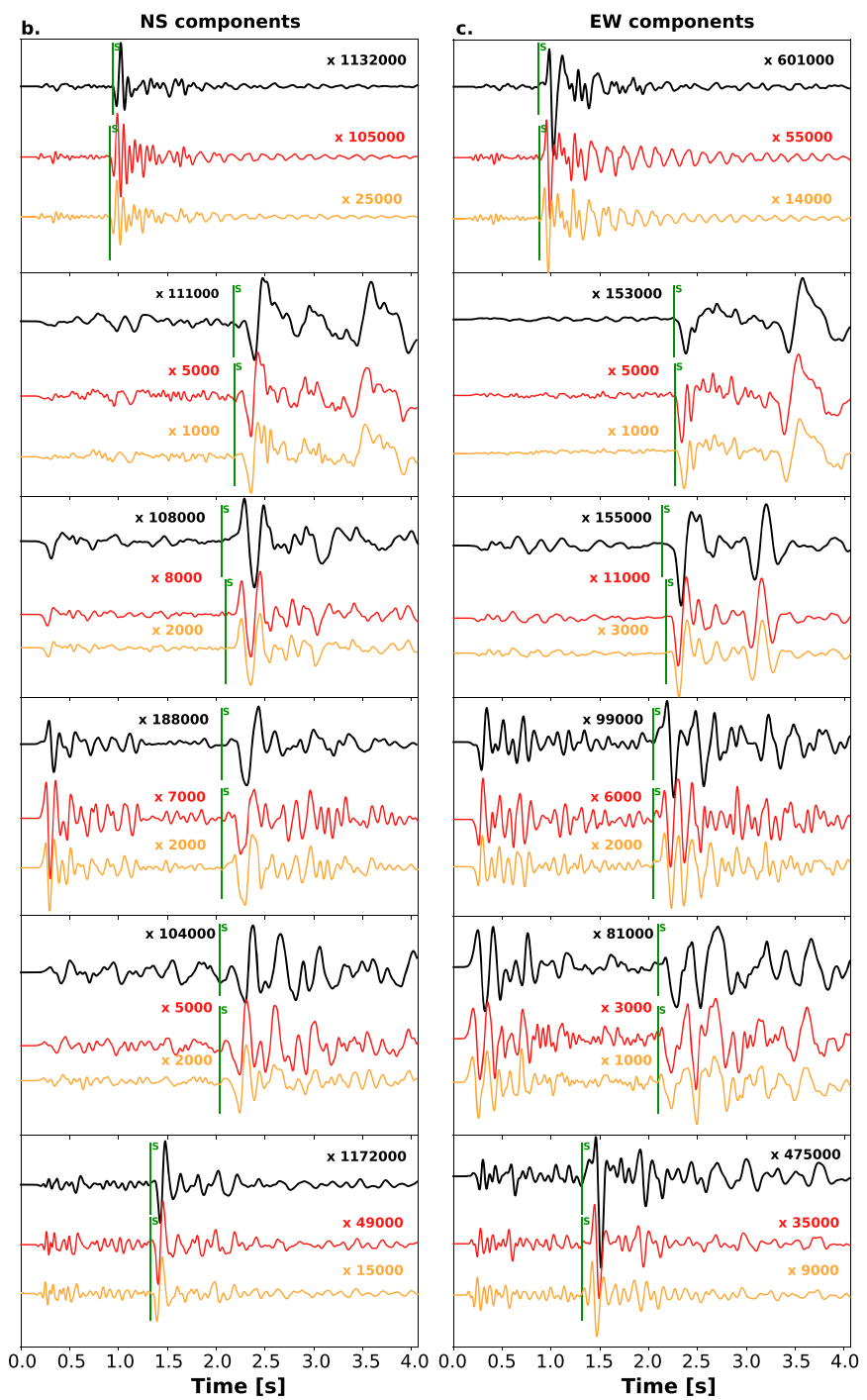

Figure 2. Waveforms of the mainshock (black), EGF1 (red), and EGF2 (orange). Signals are filtered between 0.1 and $15 \mathrm{~Hz}$ and normalized by the maximum amplitude of the given recording. (a) Vertical components for all stations, $P$ phase is indicated by vertical bars. Numbers on the right indicate the normalization factor for every signal. Dotted blue rectangles indicate the location of zooms on the mainshock waveform presented on the left. Arrows point to a small onset preceding the mainshock. (b) Same as a for north-south horizontal components. $S$ phase is indicated by vertical bars. (c) Same as b for east-west horizontal components.

activity and inducing an event of $M_{L} 2.1$ on 20 July at 2:40 a.m. (local time). At 5:30 a.m., the largest event of the sequence occurred with a magnitude of $M_{L} 3.5\left(M_{W} 3.3\right.$; Diehl et al., 2017), followed by hundreds of events in the next few months. The St. Gallen sequence ceased completely on 25 October 2013, following a production test (e.g., Moeck et al., 2015). Seismic monitoring was carried out with a local seismic network consisting of one short period borehole sensor at about 200-m depth (SGT00), five broadband surface stations (SGT01-SGT05), and additional ten short-period surface stations (SGT06-15; Kraft et al., 2013), from which SGT00 and SGT02-06 are selected for this study based on signal quality (Figures 1 and 2). Between July and November 2013, 347 earthquakes were located and subsequently finely relocated by Diehl et al. (2017). Most of the seismicity clusters in an area of roughly $0.5 \times 0.4 \mathrm{~km}^{2}$, mainly coinciding with the supposed rupture area of the largest event, inferred from scaling laws (Edwards et al., 2015). The details of the rupture process of the main event are, however, poorly known. Our goal, here, is to give insight into the rupture kinematics of the mainshock (MSH; e.g., rupture directivity and velocity) and into the spatiotemporal organization of the MSH slip on the fault, relative to the seismic events that occurred before and after. 


\section{Method}

To image the slip pattern of the main St. Gallen earthquake, we use a two-step procedure (Adinolfi et al., 2015; Stabile et al., 2012), which treats separately the problems of modeling the wave propagation and constructing the kinematic slip model. In the first step, the propagation effects are deconvolved from the recorded seismograms by applying an empirical Green's function (EGF), that is, a smaller event located close to the MSH and sharing a similar focal mechanism (e.g., Capuano et al., 1994; Courboulex et al., 1996; Hartzell, 1978; Irikura, 1983). The deconvolution process yields an apparent moment rate function at each station-carrying information on source directivity and moment release history-which we call "relative source time function" (RSTF). In the second step, the RSTFs are back-projected to the fault plane through an "isochrone back-projection" approach (IBP; Festa \& Zollo, 2006). These two steps, along with the results, are detailed in the following two sections.

\section{RSTFs and Rupture Directivity}

Recordings for the MSH, and of the two selected EGFs $\left(M_{L} 2.1-\mathrm{EGF} 1-\right.$ and $M_{L} 1.4-\mathrm{EGF} 2-$ see map in Figure 1) are shown in Figure 2. Visual comparison of the traces evidences that MSH and EGF waveforms have similar features, though MSH recordings are characterized by lower frequencies due to the extended source process. This also confirms the similar focal mechanism between MSH and EGF1 found by Diehl et al. (2017). No focal mechanism is available for EGF2, though waveform similarity indicates that it is comparable to EGF1. MSH signals present a small additional onset before the first arriving $P$ wave (Figure 2, insets), which we interpret as the $P$ wave from a small earthquake, occurring a few hundredths of seconds before the MSH.

Deconvolution of the EGF from the MSH cancels the common path and radiation pattern effects, as well as the instrumental response. The resulting RSTF represents the scalar moment release of the earthquake, distorted by the directivity effect due to the rupture propagation along the fault. Signal deconvolution is carried through the projected Landweber method (Vallée, 2004), a constrained iterative least-squares minimization approach which enforces nonnegativeness, causality, finite duration, conservation of moment ratio of the target event, and EGF (supporting information Figure S1). Traces are filtered between 0.1 and $15 \mathrm{~Hz}$, that is, below the theoretical corner frequency of the two EGFs (16 and $27 \mathrm{~Hz}$, respectively, assuming a stress drop of $3 \mathrm{MPa}$ and a shear wave velocity of $3 \mathrm{~km} / \mathrm{s}$; Edwards et al., 2015). The deconvolution is performed separately for the $P$ waves (using vertical components) and $S$ waves (using north-south and east-west components independently). In the following, we shall call the resulting $P$ wave RSTFs " $P$ RSTFs" and the $S$ wave RSTFs with north-south and east-west components "Sn RSTFs," and "Se RSTFs," respectively.

Before deconvolution, MSH and EGF traces need to be aligned. This cannot be done independently for each station, since it could produce incoherent results. We follow instead a master event approach (e.g, Grigoli et al., 2016) and search for the best centroid of MSH moment release, with respect to a fixed EGF location, as the point on the fault that better fits the relative shift between MSH and EGF $P$ wave traces (Figures S2 and S3). Centroid alignment avoids significant distortions in the RSTFs shape. Finally, to pinpoint the rupture start, the start of the EGFs is handpicked.

Figure S4 shows RSTFs obtained using EGF1 and EGF2: the overall similarity between $P$, Sn, and $S e$ RSTF for both EGFs validates the stability of the deconvolution process and the reliability of the retrieved RSTFs. The early onset on the MSH signal (shown in Figure 2) appears, after deconvolution, on the RSTFs for both EGF1 and EGF2. To image exclusively the main moment release, we pick the start of the highest moment release (vertical bars in Figure S4) and use only the remaining part of the RSTFs (Figure S5) to construct the kinematic slip model.

Figure 3 shows the final RSTFs obtained from deconvolution with EGF1, as a function of station azimuth $\theta$ from the rupture strike (N32), compared to the theoretical apparent source duration for a horizontal (i.e., along-strike) rupture propagation on a vertical fault (Haskell, 1964):

$$
T=\frac{L}{V r}-\frac{L \cos \theta}{c}
$$

where $L$ is the rupture length (200 m), $V r$ is the rupture speed $(1,500,2,000$, or 2,500 m/s), and $c$ is the $P$ or $S$ wave velocity ( 5 and $3.5 \mathrm{~km} / \mathrm{s}$, respectively). This simple analysis indicates a NNE directivity of the rupture 

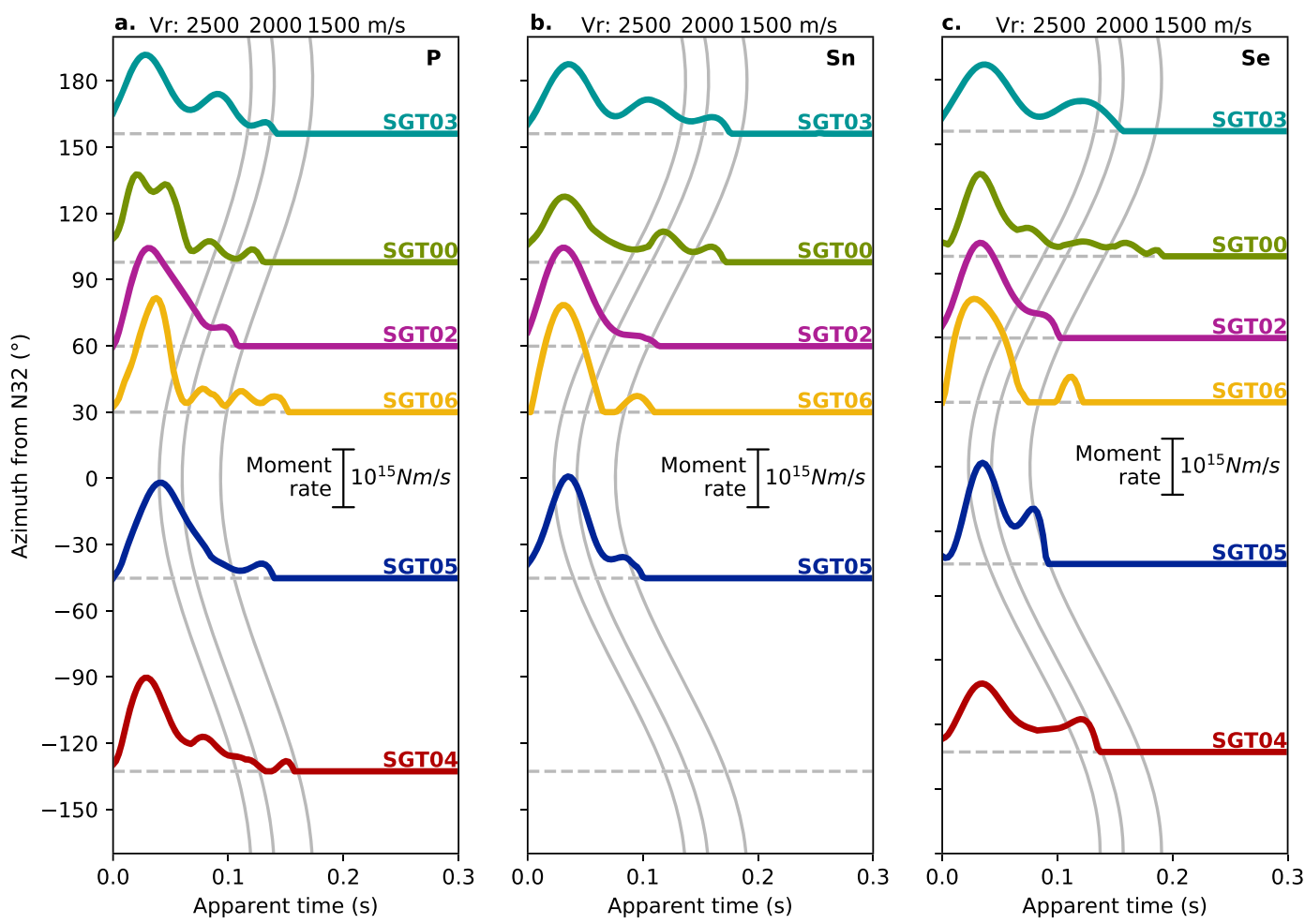

Figure 3. Relative source time functions (RSTFs) obtained using EGF1 as a function of station azimuth from the rupture strike (N32). (a) $P$ wave RSTFS (" $P$ RSTF”) obtained from deconvolution of vertical components; (b and c) $S$ wave RSTFs, obtained from deconvolution of NS ("Sn RSTF") and EW ("Se RSTF") components, respectively. Curve colors correspond to station colors in Figure 1. Sn RSTF at station SGT04 is not used due to its low quality. Gray curves indicate the theoretical apparent source duration (using the standard directivity formula; Haskell, 1964) for a rupture length of $200 \mathrm{~m}$ in N32 direction and a rupture speed $(V r)$ of 1,500, 2,000, or 2,500 m/s; $P$ and $S$ wave velocities are fixed to 5 and $3.5 \mathrm{~km} / \mathrm{s}$, respectively.

with a speed between 1,500 and $2,000 \mathrm{~m} / \mathrm{s}$. The impossibility of finding a unique rupture speed implies that the rupture process is more complex than a linear propagation, as we shall see in the following section.

\section{Kinematic Slip Model From IBP}

In the second step we seek to back-project the RSTFs on the fault plane and reconstruct, through an averaging procedure, the space-time distribution of fault slip. We set up a $600-\mathrm{m} \times 600-\mathrm{m}$ subvertical fault (dip of $\left.84^{\circ}\right)$ with 5-m $\times 5$-m uniform grid cells, centered around the hypocenter of the $\operatorname{MSH}\left(47.421073^{\circ}, 9.319911^{\circ}\right.$, depth $4.332 \mathrm{~km}$ ) (Diehl et al., 2017). Using the $P$ and $S$ wave velocity model from Diehl et al. (2017), and fixing the same constant rupture velocity in both along-dip and along-strike directions (i.e., circular rupture), the $P, S n$, and Se RSTFs are back-projected over the rupture isochrones, that is, points on the fault plane that are "seen" as rupturing at the same time from the relative station position (Bernard \& Madariaga, 1984; Spudich \& Frazer, 1984). Without any a priori information on the moment rate on the fault, the RSTFs are uniformly distributed (back-projected) on the corresponding isochrones, and the resulting moment rate map (IBP image) is the spatial average on the fault of the back-projected RSTFs. The quality of the obtained solution is computed as the mean RSTF residual, using an L1 norm for the difference between the original and the expected RSTFs, reconstructed by solving the forward problem. As discussed in Festa and Zollo (2006), the obtained IBP map is a defocused image of the actual moment rate distribution on the fault, due to the convolutional effect introduced by the isochrone geometry. An imperfect—yet effective—deconvolution is achieved through the "restarting" iterative procedure proposed by Festa and Zollo (2006): A new back-projection is performed using the previous mean IBP image as spatial weighting. With this approach, moment rate is no longer spread uniformly on the isochrones but concentrated on the zones indicated by the previous mean IBP solution (Figures S7-S9), resulting into a more focused IBP map and lower RSTFs residuals. The process is iterated while the mean RSTF residual decreases 

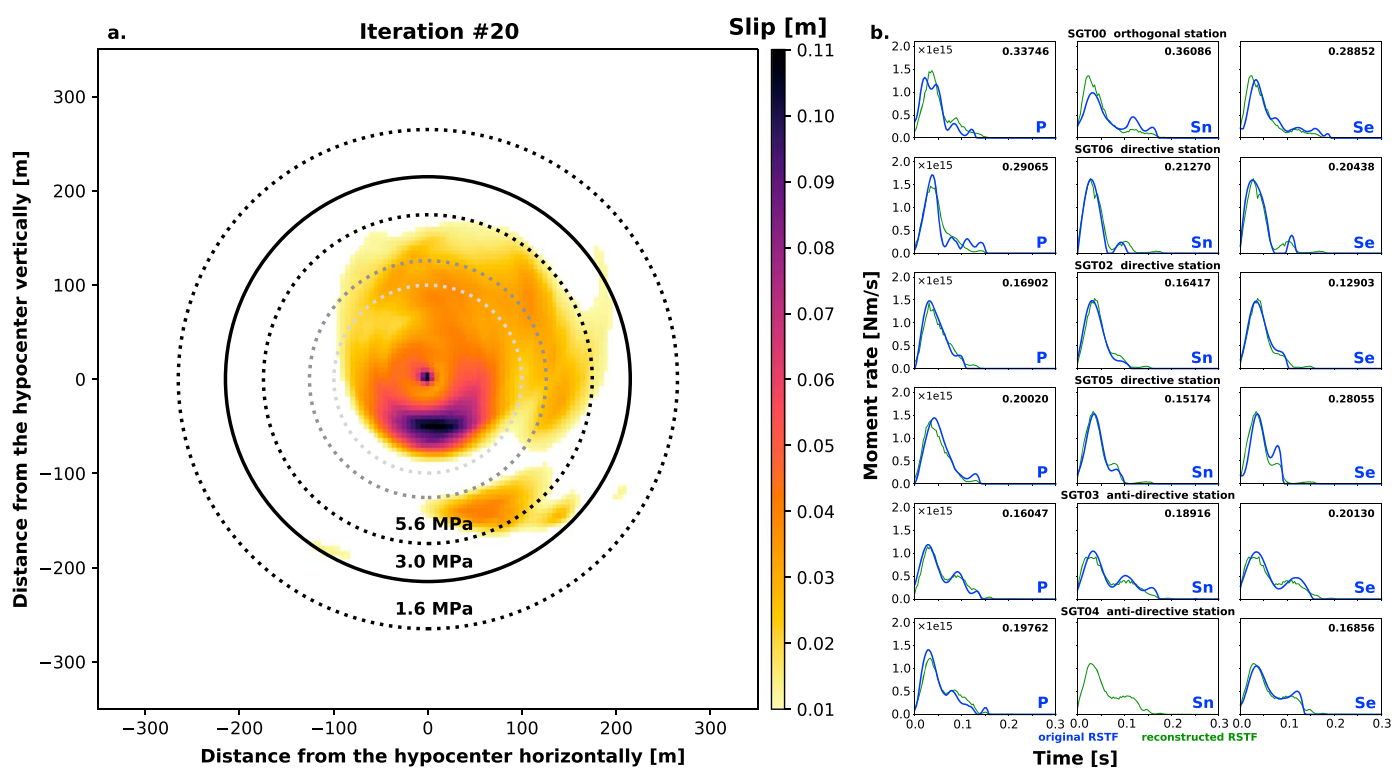

Figure 4. Results of the isochrone back-projection. (a) Slip on the fault after 20 iterations using the original RSTFs obtained by deconvolution and rupture velocity of $2,000 \mathrm{~m} / \mathrm{s}$. Slip amplitude is shown in color, as indicated by the color bar. Solid and dotted black lines denote the rupture area corresponding to stress drop of $3 \mathrm{MPa}$, and its $\pm 5 \%$ corner frequency misfit limits 1.6 and 5.6 MPa estimated by Edwards et al. (2015). Dark and light gray dotted circles correspond to the rupture area of 15 and $30 \mathrm{MPa}$, respectively. (b) P RSTFs (left column), Sn RSTFs (middle column), and Se RSTFs (right column) show the comparison of original (blue) and reconstructed (green) RSTFs at all stations. Numbers in the top right corner indicate the misfit between original and reconstructed RSTFs.

significantly (see the supporting information for more details and testing of the procedure for a synthetic case). We apply a Gaussian smoothing (with standard deviation of 0.5 grid cells) on every iteration to avoid too rough intermediate and final solutions, while keeping the same general properties of the moment rate pattern. Finally, moment rate is converted to seismic moment by assuming uniform rise time on the entire fault (equation (S22)) and to fault slip using Aki's seismic moment formula (equation (S24)).

Joint back-projection of $P$ and $S$ RSTFs, repeated for different rupture velocities, provides an optimal rupture velocity of 2,000 m/s (Figure S13) and reveals a nonuniform slip pattern with significant rupture directivity (Figure 4). The rupture initially propagated concentrically with about $10 \mathrm{~cm}$ of slip around the hypocenter, then moved toward the NNE activating an asperity about $150 \mathrm{~m}$ away from the hypocenter as well as a fairly separated patch below the main slip asperity with about $5 \mathrm{~cm}$ of slip. The bulk of the slip pattern is more compact than a circular rupture area corresponding to the stress drop values estimated by Edwards et al. (2015), which would suggest a higher local stress drop value (15-30 MPa, dark and light gray dotted circles, respectively, in Figure 4).

\section{Discussion}

According to the catalog produced by Diehl et al. (2017; magnitude of completeness: $M_{L} 0.0$ ), the main event in the St. Gallen reservoir was preceded by 61 earthquakes $\left(-0.9<M_{L}<2.1\right)$ and was followed by 282 events $\left(-1.2<M_{L}<1.7\right)$. For simplicity, we call these events "foreshocks" and "aftershocks", respectively, referring solely to their origin time relative to the MSH. The space-time seismicity pattern is shown in Figure 5, with symbol sizes corresponding to rupture area, assuming a stress drop of $3 \mathrm{MPa}$ and using Eshelby's formula (equation (S27)); T0 is the timing of the MSH. Early events (6 days to $10 \mathrm{hr}$ before T0, Figure 5a) occur to the SSW of the MSH rupture. Their locations might be explained by stress concentration on the edges of a locked part of the fault, as suggested by Diehl et al. (2017). Note that there is no direct contact between the seismicity cloud and the openhole section of the well, but hydraulic connection must be already established as seismicity reacts promptly to stimulation procedures (Diehl et al., 2017). Later foreshocks ( $\sim 10 \mathrm{hr}$ to 3 min before T0) migrate toward the middle of the MSH slip patch, in what could be interpreted as a slow nucleation phase: The main rupture initiates at the location of the largest foreshock $\left(M_{L} 2.1\right.$, EGF1 in this study), and the bulk of slip coincides with the foreshock location. On the other hand, the slip to the NNE 


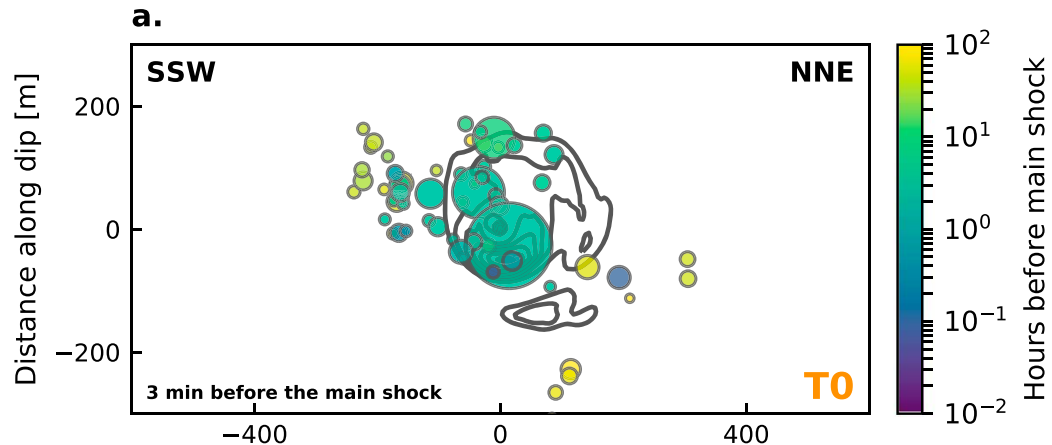

b.

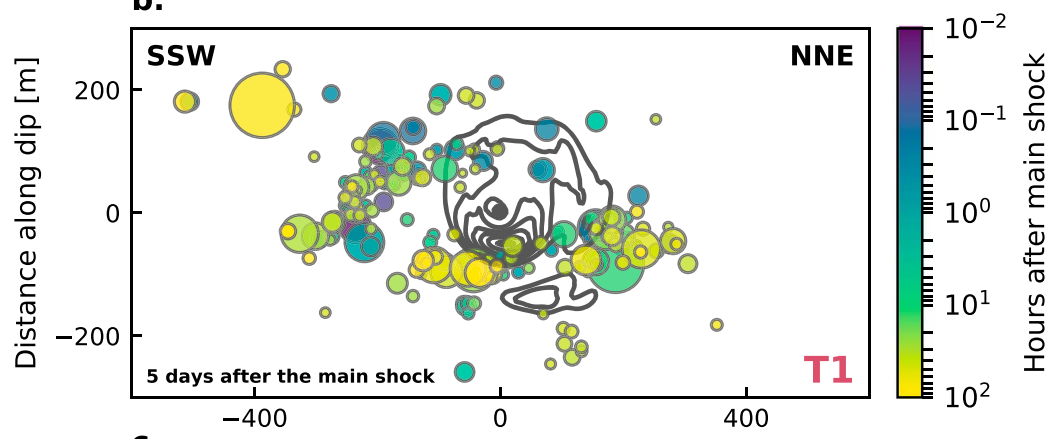

C.

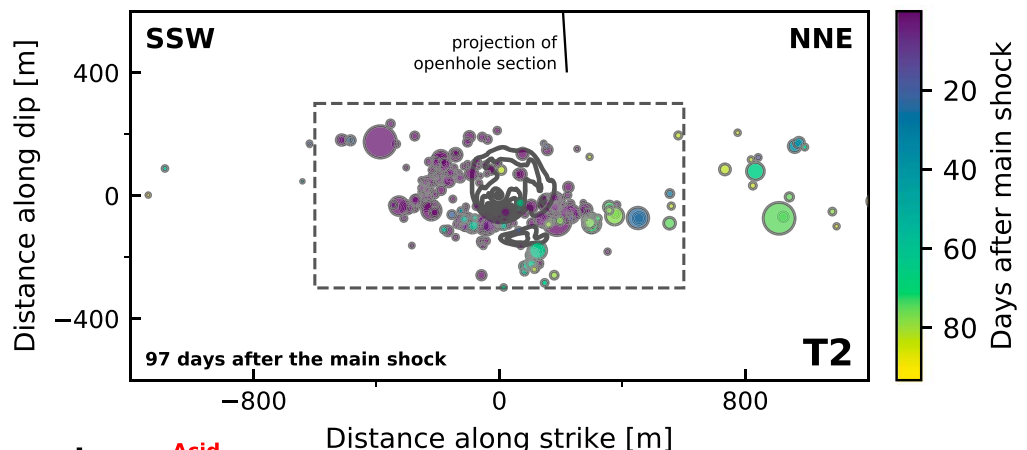

d. Acid $\begin{gathered}\text { Acions } \\ \text { stimulations }\end{gathered}$

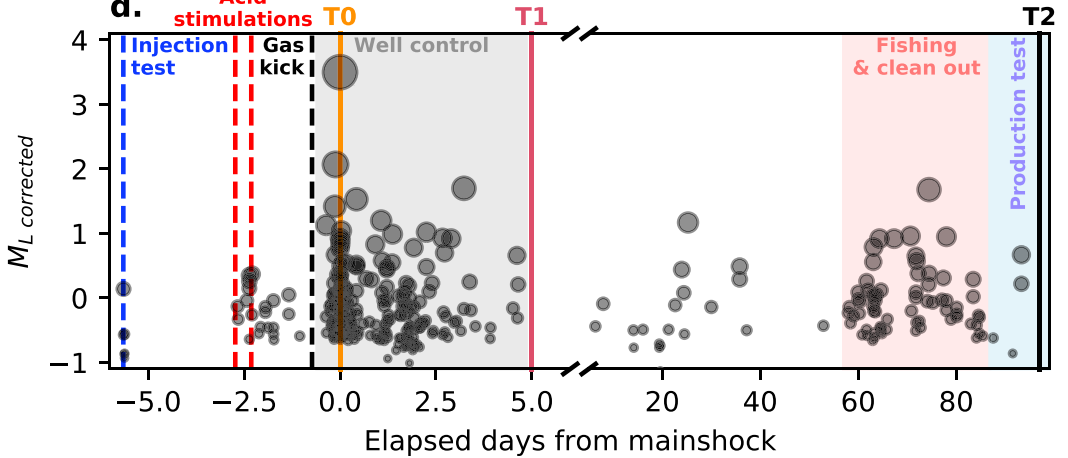

Figure 5. Comparison of slip pattern of the mainshock with micro-earthquakes (Diehl et al., 2017). (a) Events 3 min before the mainshock (T0) on the fault. Colors of the slip patches correspond to timing with respect to the mainshock shown by the color bar. Dark colors indicate proximity to the mainshock. Size of the micro-earthquakes correspond to the rupture areas supposing $3 \mathrm{MPa}$ of stress drop for all events. Solid black lines indicate equivalent displacement of the main slip. (b) Same as a with seismicity that occurred within about 5 days after the mainshock (T1). Note that the colorbar is reversed keeping the indication of dark colors. (c) Zoom out on the fault with seismicity that occurred within about 3 months after the mainshock, dashed rectangle shows the fault areas represented in a and $\mathrm{b}$. solid black line indicates the projection of the openhole section of the well. (d) Time-magnitude plot of seismicity and well operations relative to the origin time of the mainshock. 
appears to be complementary to the foreshock distribution. Early aftershocks (up to 5 days after T0) are mainly located around the MSH slip area (Figure 5b). Later aftershocks correspond to additional activities in the well (e.g., "fishing” for lost objects, cleaning, and production) and expand over a larger fault area, from SSW to NNE, with a significantly higher activity toward the NNE (Figure 5c). Diehl et al. (2017) already hypothesized that aftershock migration toward the NNE might have happened due to the gas kick that could alter hydraulic conditions or due to the main event that caused changes in hydraulic diffusivity by breaking a previously impermeable seal (possibly a NS striking fault). Our results suggest the plausibility of the latter hypothesis: it seems probable that the updip and NNE propagating MSH released a previously less active segment of the fault where significant seismicity occurred after the main event.

The observation of complementary organization of MSH slip and aftershocks is not new in the context of natural events, for example, $M_{L} 5.8$ Coyote Lake (1979), California; $M_{L} 6.2$ Morgan Hill (1984), California (Bakun et al., 1986); $M_{s} 7.3$ Borah Peak (1983), Idaho; $M_{s} 6.0$ North Palm Springs (1986), California (Mendoza \& Hartzell, 1988); $M_{s} 8.1$ Michoacan (1985), Mexico (Das, 2003; Mendoza \& Hartzell, 1989); $M_{w} 7.3$ Landers (1992), California (Das, 2003); $M_{w} 8.1$ Antarctic Plate (1998; Das, 2003); $M_{w} 6.3$ L'Aquila (2009), Italy (Chiarabba et al., 2009); $M_{w} 2.9$ Irpinia (2008), Italy (Stabile et al., 2012); and $M_{w} 9.0$ Tohoku-Oki (2011), Japan (Kato \& Igarashi, 2012). Complementary patterns between early aftershocks and coseismic slip have also been recently observed for the induced $M_{w} 4.0$ earthquake near Guthrie, Oklahoma (Wu et al., 2019). These observations are often explained by the idea that aftershocks occur where stress level is high after the MSH. These areas tend to be near the edges of the coseismic slip due to the increased loading on unbroken or partially broken barriers or in the region of rapid transition from high to low slip (Das, 2003; Mendoza \& Hartzell, 1988). In the case of fluid-induced earthquakes, evolution of pore pressure due to fluid injection must play a role in the spatiotemporal occurrence of aftershocks, in addition to static or dynamic stress transfer from the MSH. To understand the role of the governing physical processes in the St. Gallen sequence, detailed geomechanical modeling is being carried out. It is worth stressing here the importance of a detailed MSH slip model: Using a homogeneous circular or rectangular rupture area might lead to misinterpretation of reservoir size and localized seismic slip (Figure S15).

The inferred rupture model indicates directivity toward the injection well (Figures 1 and $5 \mathrm{c}$ ), that is, "backward" rupture, following the terminology of Lui and Huang (2019). According to the 1-D numerical models of Dempsey and Suckale (2016), this would imply a high pressurization/criticality ratio (i.e., the ratio between injection pressure and initial fault stress) for the St. Gallen geothermal site.

\section{Conclusions}

Small earthquakes $(M<4)$ reveal their rupture complexity when observed close and when path effects are properly accounted for (e.g., by EGFs).

By retrieving RSTFs and back-projecting them to fault isochrones, we unraveled a two-stage rupture process for the $M_{w} 3.3$ induced St. Gallen earthquake: (1) The bulk of the MSH slip $(\sim 10 \mathrm{~cm})$ takes place around the hypocenter, suggesting higher local stress drop (15-30 MPa), and (2) the rupture further propagates $\sim 150 \mathrm{~m}$ toward NNW at $2,000 \mathrm{~m} / \mathrm{s}$.

Spatiotemporal organization of microseismicity before and after the MSH shows that (1) foreshocks migrated into the bulk of MSH slip area a few hours before the main rupture, evidencing a possible slow nucleation process; (2) the MSH broke-and possibly unsealed-a previously less active portion of the fault; and (3) aftershocks distribute around MSH slip area, suggesting that stress transfer from the MSH played a major role in the sequence.

The method presented here requires a high-quality-yet standard—microseismic monitoring system and low computational power, making it possible to implement the algorithm in an operational environment. This would allow for rapid assessment of fault asperities and structures involved in the reservoir creation process. Detailed slip models for fluid-induced events could further help in understanding the relationship between the location of seismic slip and fracture connectivity, retrieved through tracer tests (Hirschberg et al., 2015). This, in turn, might help in the future to define fluid paths in the reservoir prior to tracer tests and might give some hints about the optimal location of new boreholes. 


\section{Acknowledgments}

We acknowledge financial support from the GEOTHERM-2 project and the European Union's Horizon 2020 research and innovation programme (DESTRESS project, grant agreement No. 691728). Seismic data are publicly available from Swiss Seismological Service (SED) at ETH Zurich (1983). RSTFs and slip models from this work are available from the website https:// doi.org/10.5281/zenodo.3245487. We acknowledge the operator St.Galler Stadtwerke for access to data and information. Conversion of latitude-longitude to Swiss coordinates was done using http://tool-online. com/en/coordinate-converter.php. The map of the study area was compiled using the following resources: map tiles by Stamen Design (https:// stamen.com), under CC BY 3.0., settlements by OpenStreetMap (https://www.openstreetmap.org), under the Open Database License, and roads and railways by https:// opendata.swiss, under Open use BY ASK. Data analysis was implemented using Python and the Numpy (Oliphant, 2007) and ObsPy (Krischer et al., 2015) libraries. Figures were prepared using Matplotlib (Hunter, 2007). We are grateful for discussions with Tobias Diehl, Toni Kraft, Martin Mai, Antonella Orefice, Tony Alfredo Stabile, and Martin Vallée during the preparation of the manuscript. We are also grateful to two anonymous reviewers and to Editor Gavin Hayes for their comments and suggestions which helped improve the manuscript.

\section{References}

Abercrombie, R. E., Poli, P., \& Bannister, S. (2017). Earthquake directivity, orientation, and stress drop within the subducting plate at the Hikurangi Margin, New Zealand. Journal of Geophysical Research: Solid Earth, 122, 10,176-10,188. https://doi.org/10.1002/ 2017JB014935

Adinolfi, G. M., Matteis, R. D., Orefice, A., Festa, G., Zollo, A., de Nardis, R., \& Lavecchia, G. (2015). The September 27, 2012, $M_{L}$ 4.1, Benevento earthquake: A case of strike-slip faulting in Southern Apennines (Italy). Tectonophysics, 660, 35-46. https://doi.org/10.1016/ j.tecto.2015.06.036

Albaric, J., Oye, V., Langet, N., Hasting, M., Lecomte, I., Iranpour, K., et al. (2014). Monitoring of induced seismicity during the first geothermal reservoir stimulation at Paralana, Australia. Geothermics, 52, 120-131. https://doi.org/10.1016/j.geothermics.2013.10.013

Atkinson, G. M., Eaton, D. W., Ghofrani, H., Walker, D., Cheadle, B., Schultz, R., et al. (2016). Hydraulic fracturing and seismicity in the Western Canada Sedimentary Basin. Seismological Research Letters, 87(3), 631-647. https://doi.org/10.1785/0220150263

Bachmann, C. E., Wiemer, S., Woessner, J., \& Hainzl, S. (2011). Statistical analysis of the induced Basel 2006 earthquake sequence: Introducing a probability-based monitoring approach for enhanced geothermal systems. Geophysical Journal International, 186(2), 793-807. https://doi.org/0.1111/j.1365-246x.2011.05068.x

Baisch, S., Voros, R., Weidler, R., \& Wyborn, D. (2009). Investigation of fault mechanisms during geothermal reservoir stimulation experiments in the Cooper Basin, Australia. Bulletin of the Seismological Society of America, 99(1), 148-158. https://doi.org/10.1785/ 0120080055

Bakun, W. H., King, G. C. P., \& Cockerham, R. S. (1986). Seismic slip, aseismic slip, and the mechanics of repeating earthquakes on the Calaveras Fault, California, Earthquake source mechanics (pp. 195-207): American Geophysical Union. https://doi.org/10.1029/ gm037p0195

Bernard, P, \& Madariaga, R (1984). A new asymptotic method for the modeling of near-field accelerograms. Bulletin of the Seismological Society of America, 74(2), 539-557.

Boatwright, J. (2007). The persistence of directivity in small earthquakes. Bulletin of the Seismological Society of America, 97(6), $1850-1861$. https://doi.org/10.1785/0120050228

Capuano, P., Zollo, A., \& Singh, S. K. (1994). Source characteristics of moderate size events using empirical Green functions: An application to some Guerrero (Mexico) subduction zone earthquakes. Annals of Geophysics, 37(6). http://doi.org/10.4401/ag-4153

Catalli, F., Rinaldi, A. P., Gischig, V., Nespoli, M., \& Wiemer, S. (2016). The importance of earthquake interactions for injection-induced seismicity: Retrospective modeling of the Basel Enhanced Geothermal System. Geophysical Research Letters, 43, 4992-4999. https://doi. org/10.1002/2016GL068932

Chiarabba, C., Amato, A., Anselmi, M., Baccheschi, P., Bianchi, I., Cattaneo, M., et al. (2009). The 2009 L'Aquila (central Italy) $M_{W} 6.3$ earthquake: Main shock and aftershocks. Geophysical Research Letters, 36, L18308. https://doi.org/10.1029/2009GL039627

Courboulex, F., Virieux, J., Deschamps, A., Gibert, D., \& Zollo, A. (1996). Source investigation of a small event using empirical Green's functions and simulated annealing. Geophysical Journal International, 125(3), 768-780. https://doi.org/10.1111/j.1365-246x.1996. tb06022.x

Das, S. (2003). Spatial relation between main earthquake slip and its aftershock distribution. Reviews of Geophysics, 41(3), 1013. https:// doi.org/10.1029/2002rg000119

Deichmann, N., \& Giardini, D. (2009). Earthquakes induced by the stimulation of an enhanced geothermal system below Basel (Switzer land). Seismological Research Letters, 80(5), 784-798. https://doi.org/10.1785/gssrl.80.5.784

Deichmann, N., Kraft, T., \& Evans, K. F. (2014). Identification of faults activated during the stimulation of the Basel geothermal project from cluster analysis and focal mechanisms of the larger magnitude events. Geothermics, 52, 84-97. https://doi.org/10.1016/j.geothermics. 2014.04.001

Dempsey, D., \& Suckale, J. (2016). Collective properties of injection-induced earthquake sequences: 1. Model description and directivity bias. Journal of Geophysical Research: Solid Earth, 121, 3609-3637. https://doi.org/10.1002/2015JB012550

Diehl, T., Kraft, T., Kissling, E., \& Wiemer, S. (2017). The induced earthquake sequence related to the St. Gallen deep geothermal project (Switzerland): Fault reactivation and fluid interactions imaged by microseismicity. Journal of Geophysical Research: Solid Earth, 122 7272-7290. https://doi.org/10.1002/2017JB014473

Dreger, D., Nadeau, R. M., \& Chung, A. (2007). Repeating earthquake finite source models: Strong asperities revealed on the San Andreas Fault. Geophysical Research Letters, 34, L23302. https://doi.org/10.1029/2007GL031353

Edwards, B., \& Douglas, J. (2014). Magnitude scaling of induced earthquakes. Geothermics, 52, 132-139. https://doi.org/10.1016/j. geothermics.2013.09.012

Edwards, B., Kraft, T., Cauzzi, C., Kastli, P., \& Wiemer, S. (2015). Seismic monitoring and analysis of deep geothermal projects in St Gallen and Basel, Switzerland. Geophysical Journal International, 201(2), 1022-1039. https://doi.org/10.1093/gji/ggv059

Ellsworth, W. L. (2013). Injection-induced earthquakes. Science, 341(6142), 1225942. https://doi.org/10.1126/science.1225942

Evans, K. F., Zappone, A., Kraft, T., Deichmann, N., \& Moia, F. (2012). A survey of the induced seismic responses to fluid injection in geothermal and $\mathrm{CO}_{2}$ reservoirs in Europe. Geothermics, 41, 30-54. https://doi.org/10.1016/j.geothermics.2011.08.002

Festa, G., \& Zollo, A. (2006). Fault slip and rupture velocity inversion by isochrone backprojection. Geophysical Journal International, 166(2), 745-756. https://doi.org/10.1111/j.1365-246x.2006.03045.x

Gischig, V. S., \& Wiemer, S. (2013). A stochastic model for induced seismicity based on non-linear pressure diffusion and irreversible permeability enhancement. Geophysical Journal International, 194(2), 1229-1249. https://doi.org/10.1093/gji/ggt164

Goertz-Allmann, B. P., Goertz, A., \& Wiemer, S. (2011). Stress drop variations of induced earthquakes at the Basel geothermal site. Geophysical Research Letters, 38, L09308. https://doi.org/10.1029/2011GL047498

Grigoli, F., Cesca, S., Krieger, L., Kriegerowski, M., Gammaldi, S., Horalek, J., et al. (2016). Automated microseismic event location using Master-Event Waveform Stacking. Scientific Reports, 6(1). https://doi.org/10.1038/srep25744

Grigoli, F., Cesca, S., Priolo, E., Rinaldi, A. P., Clinton, J. F., Stabile, T. A., et al. (2017). Current challenges in monitoring, discrimination, and management of induced seismicity related to underground industrial activities: A European perspective. Reviews of Geophysics, 55 310-340. https://doi.org/10.1002/2016RG000542

Guilhem, A., \& Walter, F. (2015). Full, constrained and stochastic source inversions support evidence for volumetric changes during the Basel earthquake sequence. Swiss Journal of Geosciences, 108(2-3), 361-377. https://doi.org/10.1007/s00015-015-0197-9

Hartzell, S. H. (1978). Earthquake aftershocks as Green's functions. Geophysical Research Letters, 5(1), 1-4. https://doi.org/10.1029/ gl005i001p00001 
Haskell, N. A. (1964). Total energy and energy spectral density of elastic wave radiation from propagating faults. Bulletin of the Seismological Society of America, 54(6A), 1811.

Heuberger, S., Roth, P., Zingg, O., Naef, H., \& Meier, B. P. (2016). The St. Gallen Fault Zone: A long-lived, multiphase structure in the North Alpine Foreland Basin revealed by 3D seismic data. Swiss Journal of Geosciences, 109(1), 83-102. https://doi.org/10.1007/ s00015-016-0208-5

Hirschberg, S., Wiemer, S., \& Burgherr, P. (2015). Energy from the Earth-Deep geothermal as a resource for the future? Die Deutsche Nationalbibliothek. https://doi.org/10.3218/3655-8

Huang, Y., Ellsworth, W. L., \& Beroza, G. C. (2017). Stress drops of induced and tectonic earthquakes in the central United States are indistinguishable. Science Advances, 3(8), e1700772. https://doi.org/10.1126/sciadv.1700772

Hunter, J. D. (2007). Matplotlib: A 2D graphics environment. Computing in Science \& Engineering, 9(3), 90-95. https://doi.org/10.1109/ mcse. 2007.55

Ide, S. (2001). Complex source processes and the interaction of moderate earthquakes during the earthquake swarm in the Hida-Mountains, Japan, 1998. Tectonophysics, 334(1), 35-54. https://doi.org/10.1016/s0040-1951(01)00027-0

Irikura, K. (1983). Semi-empirical estimation of strong earthquakes ground motions during large earthquakes. Bulletin of the Disaster Prevention Research Institute, 33(2), 63-104.

Karvounis, D. C., \& Wiemer, S. (2015). Decision making software for forecasting induced seismicity and thermal energy revenues in enhanced geothermal systems. In Proceedings world geothermal congress 2015, Melbourne, Australia, pp. 10.

Kato, A., \& Igarashi, T. (2012). Regional extent of the large coseismic slip zone of the $2011 M_{w} 9.0$ Tohoku-Oki earthquake delineated by on-fault aftershocks. Geophysical Research Letters, 39, L15301. https://doi.org/10.1029/2012gl052220

Kim, A., Dreger, D. S., Taira, T., \& Nadeau, R. M. (2016). Changes in repeating earthquake slip behavior following the 2004 Parkfield main shock from waveform empirical Green's functions finite-source inversion. Journal of Geophysical Research: Solid Earth, 121, 1910-1926. https://doi.org/10.1002/2015JB012562

Kraft, T., \& Deichmann, N. (2014). High-precision relocation and focal mechanism of the injection-induced seismicity at the Basel EGS Geothermics, 52, 59-73. https://doi.org/10.1016/j.geothermics.2014.05.014

Kraft, T., Wiemer, S., Deichmann, N., Diehl, T., Edwards, B., Guilhem, A., et al. (2013). The ML 3.5 earthquake sequence induced by the hydrothermal energy project in St. Gallen, Switzerland. Agu fall meeting abstracts, 2013, S31F03.

Krischer, L., Megies, T., Barsch, R., Beyreuther, M., Lecocq, T., Caudron, C., \& Wassermann, J. (2015). ObsPy: A bridge for seismology into the scientific Python ecosystem. Computational Science \& Discovery, 8(1), 014003. https://doi.org/10.1088/1749-4699/8/1/014003

Langenbruch, C., \& Shapiro, S. A. (2010). Decay rate of fluid-induced seismicity after termination of reservoir stimulations. Geophysics, 75(6), MA53-MA62. https://doi.org/10.1190/1.3506005

Langenbruch, C., \& Zoback, M. D. (2016). How will induced seismicity in Oklahoma respond to decreased saltwater injection rates? Science Advances, 2(11), e1601542. https://doi.org/10.1126/sciadv.1601542

Lui, SemechahK. Y., \& Huang, Y. (2019). Do injection-induced earthquakes rupture away from injection wells due to fluid pressure change? Bulletin of the Seismological Society of America, 109(1), 358-371. https://doi.org/10.1785/0120180233

Mai, P. M. (2005). Hypocenter locations in finite-source rupture models. Bulletin of the Seismological Society of America, 95(3), 965-980. https://doi.org/10.1785/0120040111

McGuire, J. J. (2002). Predominance of unilateral rupture for a global catalog of large earthquakes. Bulletin of the Seismological Society of America, 92(8), 3309-3317. https://doi.org/10.1785/0120010293

McGuire, J. J. (2004). Estimating finite source properties of small earthquake ruptures. Bulletin of the Seismological Society of America, 94(2), 377-393. https://doi.org/10.1785/0120030091

Mena, B., Wiemer, S., \& Bachmann, C. (2013). Building robust models to forecast the induced seismicity related to geothermal reservoir enhancement. Bulletin of the Seismological Society of America, 103(1), 383-393. https://doi.org/10.1785/0120120102

Mendoza, C., \& Hartzell, S. H. (1988). Aftershock patterns and main shock faulting. Bulletin of the Seismological Society of America, 78(4), $1438-1449$.

Mendoza, C, \& Hartzell, S. (1989). Slip distribution of the 19 September 1985 Michoacan, Mexico, earthquake: Near-source and teleseismic constraints. Bulletin of the Seismological Society of America, 79(3), 655-669.

Moeck, I., Bloch, T., Graf, R., Heuberger, S., Kuhn, P., Naef, H., et al. (2015). The St. Gallen project: Development of fault controlled geothermal systems in urban areas. In Proceedings world geothermal congress, Melbourne, Australia, pp. 1-5.

Oliphant, T. E. (2007). Python for scientific computing. Computing in Science \& Engineering, 9(3), 10-20. https://doi.org/10.1109/mcse. 2007.58

Rutqvist, J. (2011). Status of the TOUGH-FLAC simulator and recent applications related to coupled fluid flow and crustal deformations. Computers \& Geosciences, 37(6), 739-750. https://doi.org/10.1016/j.cageo.2010.08.006

Schoenball, M., Walsh, F. R., Weingarten, M., \& Ellsworth, W. L. (2018). How faults wake up: The Guthrie-Langston, Oklahoma earthquakes. The Leading Edge, 37(2), 100-106. https://doi.org/10.1190/tle37020100.1

Segall, P., \& Lu, S. (2015). Injection-induced seismicity: Poroelastic and earthquake nucleation effects. Journal of Geophysical Research: Solid Earth, 120, 5082-5103. https://doi.org/10.1002/2015JB012060

Spudich, P., \& Frazer, LNeil (1984). Use of ray theory to calculate high-frequency radiation from earthquake sources having spatially variable rupture velocity and stress drop. Bulletin of the Seismological Society of America, 74(6), 2061-2082.

Stabile, T. A., Satriano, C., Orefice, A., Festa, G., \& Zollo, A. (2012). Anatomy of a microearthquake sequence on an active normal fault. Scientific Reports, 2(1). https://doi.org/10.1038/srep00410

Stein, R. S. (2003). Earthquake conversations. Scientific American, 288(1), 72-79. https://doi.org/10.1038/scientificamerican0103-72

Swiss Seismological Service (SED) at ETH Zurich (1983). National seismic networks of Switzerland, ETH Zürich. Other/Seismic Network. https://doi.org/10.12686/sed/networks/ch

Vallée, M. (2004). Stabilizing the empirical Green function analysis: Development of the projected Landweber method. Bulletin of the Seismological Society of America, 94(2), 394-409. https://doi.org/10.1785/0120030017

Wolfgramm, M., Bloch, T., Bartels, J., Heuberger, S., Kuhn, P., Naef, H., et al. (2015). Reservoir-geological characterization of a fractured limestone: Results obtained from the geothermal Well St. Gallen GT-1 (Switzerland). In World geothermal congress 2015, Melbourne, Australia, pp. 12.

Wu, Q., Chen, X., \& Abercrombie, R. E. (2019). Source complexity of the $2015 M_{w} 4.0$ Guthrie, Oklahoma earthquake. Geophysical Research Letters, 46, 4674-4684. https://doi.org/10.1029/2019GLs082690 